University of Wollongong

Research Online

Faculty of Social Sciences - Papers (Archive) Faculty of Arts, Social Sciences \& Humanities

2006

A novel in vitro exposure technique for toxicity testing of selected volatile organic compounds

\author{
Shahnaz Bakand \\ University of Wollongong, sbakand@uow.edu.au \\ Chris Winder \\ University of New South Wales \\ Christian Khalil \\ University of New South Wales \\ Amanda Hayes \\ University of New South Wales
}

Follow this and additional works at: https://ro.uow.edu.au/sspapers

Part of the Education Commons, and the Social and Behavioral Sciences Commons

Research Online is the open access institutional repository for the University of Wollongong. For further information contact the UOW Library: research-pubs@uow.edu.au 


\title{
A novel in vitro exposure technique for toxicity testing of selected volatile organic compounds
}

\author{
Abstract \\ Exposure to vapours of volatile chemicals is a major occupational and environmental health concern. \\ Toxicity testing of volatile organic compounds (VOCs) has always faced significant technological \\ problems due to their high volatility and/or low solubility. The aim of this study was to develop a practical \\ and reproducible in vitro exposure technique for toxicity testing of VOCs. Standard test atmospheres of \\ xylene and toluene were generated in glass chambers using a static method. Human cells including: \\ A549-lung derived cell lines, HepG2-liver derived cell lines and skin fibroblasts, were grown in porous \\ membranes and exposed to various airborne concentrations of selected VOCs directly at the air/liquid \\ interface for $1 \mathrm{~h}$ at $37^{\circ} \mathrm{C}$. Cytotoxicity of test chemicals was investigated using the MTS \\ (3-(4,5-dimethylthiazol-2-yl)-5-(3-carboxymethoxyphenyl)-2-(4-sulfophenyl)-2H-tetrazolium) and NRU \\ (neutral red uptake) assays following $24 \mathrm{~h}$ incubation. Airborne $\mathrm{IC}_{50}$ (50\% inhibitory concentration) values \\ were determined using dose response curves for xylene ( $I_{50}=5350 \pm 328 \mathrm{ppm}, \mathrm{NRU}$; IC $50=5750 \pm 433$ \\ ppm, MTS in skin fibroblast) and toluene (IC $50=10500 \pm 527$ ppm, NRU; IC $50=11200 \pm 1044$ ppm, MTS in \\ skin fibroblast). Our findings suggest that static direct exposure at the air/liquid interface is a practical \\ and reproducible technique for toxicity testing of VOCs. Further, this technique can be used for \\ inhalational and dermal toxicity studies of volatile chemicals in vitro as the exposure pattern in vivo is \\ closely simulated by this method.
}

\section{Keywords}

vitro, exposure, technique, toxicity, novel, testing, compounds, selected, volatile, organic

\author{
Disciplines \\ Education | Social and Behavioral Sciences
}

\section{Publication Details}

Bakand, S., Winder, C., Khalil, C. \& Hayes, A. (2006). A novel in vitro exposure technique for toxicity testing of selected volatile organic compounds. Journal of Environmental Monitoring, 8 (1), 100-105. 


\title{
A novel in vitro exposure technique for toxicity testing of selected volatile organic compounds $\dagger$
}

\author{
S. Bakand,* C. Winder, C. Khalil and A. Hayes \\ Received 11th July 2005, Accepted 17th October 2005 \\ First published as an Advance Article on the web 9th November 2005 \\ DOI: $10.1039 / \mathbf{b 5 0 9 8 1 2 b}$
}

Exposure to vapours of volatile chemicals is a major occupational and environmental health concern. Toxicity testing of volatile organic compounds (VOCs) has always faced significant technological problems due to their high volatility and/or low solubility. The aim of this study was to develop a practical and reproducible in vitro exposure technique for toxicity testing of VOCs. Standard test atmospheres of xylene and toluene were generated in glass chambers using a static method. Human cells including: A549-lung derived cell lines, HepG2-liver derived cell lines and skin fibroblasts, were grown in porous membranes and exposed to various airborne concentrations of selected VOCs directly at the air/liquid interface for $1 \mathrm{~h}$ at $37{ }^{\circ} \mathrm{C}$. Cytotoxicity of test chemicals was investigated using the MTS (3-(4,5-dimethylthiazol-2-yl)-5-(3-

carboxymethoxyphenyl)-2-(4-sulfophenyl)-2 $H$-tetrazolium) and NRU (neutral red uptake) assays following $24 \mathrm{~h}$ incubation. Airborne $\mathrm{IC}_{50}$ (50\% inhibitory concentration) values were determined using dose response curves for xylene $\left(\mathrm{IC}_{50}=5350 \pm 328 \mathrm{ppm}, \mathrm{NRU} ; \mathrm{IC}_{50}=5750 \pm 433 \mathrm{ppm}\right.$, MTS in skin fibroblast) and toluene $\left(\mathrm{IC}_{50}=10500 \pm 527 \mathrm{ppm}, \mathrm{NRU} ; \mathrm{IC}_{50}=11200 \pm 1044\right.$ ppm, MTS in skin fibroblast). Our findings suggest that static direct exposure at the air/liquid interface is a practical and reproducible technique for toxicity testing of VOCs. Further, this technique can be used for inhalational and dermal toxicity studies of volatile chemicals in vitro as the exposure pattern in vivo is closely simulated by this method.

\section{Introduction}

Volatile organic compounds (VOCs), such as organic solvents, are chemical compounds with widespread applications in: metal cleaning, surface coating, dry cleaning, adhesives, chemical intermediates, motor fuels, pharmaceutical and consumer products. ${ }^{1}$ Occupational and environmental exposures to VOCs are a significant contributor to human health problems. ${ }^{1,2}$ Inhalational and dermal exposure to these chemicals can cause both local and systemic toxic effects. The lungs, skin, central nervous system (CNS), liver and the kidneys are the main body systems affected by these chemicals. ${ }^{1}$ Despite the importance of VOCs, in vitro toxicity testing of these compounds has encountered significant technical challenges due to their physicochemical properties. ${ }^{3-6}$

Low water solubility and high vapour pressure are two major physico-chemical characteristics of many VOCs that may create technical challenges during the course of in vitro experimentation. Conventionally, insoluble test chemicals are solubilised in culture media using a range of organic solvents such as dimethyl sulfoxide (DMSO) or alcohols. ${ }^{7}$ However, the use of a solvent can potentially increase experimental errors, influence the observed toxicity and interfere with end-

Chemical Safety and Applied Toxicology (CSAT) Laboratories, School of Safety Science, The University of New South Wales, UNSW, Sydney, 2052, Australia

$\dagger$ Presented at the Fifth International Symposium on Modern Principles of Air Monitoring \& Biomonitoring, June 12-16 2005, Norway. point measurements. Sonication can also be used to improve the solubility of immiscible organic compounds such as xylene and malathion. ${ }^{8}$ Nevertheless, the resulting chemical mixture can still separate during the incubation period.

High volatilisation of the test chemical from the exposure medium is another experimental problem that occurs while conducting in vitro experiments with volatile compounds. This may result in a significant loss of the test chemical and cross

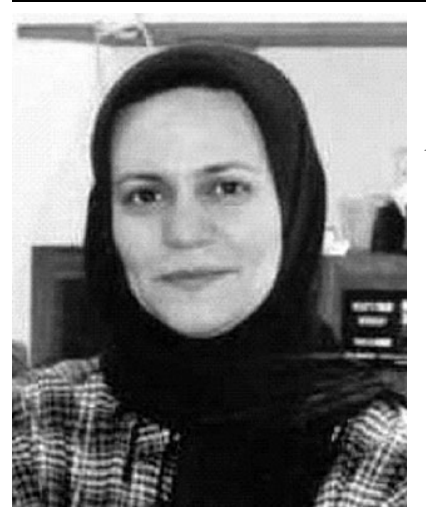

Shahnaz Bakand has a Masters in Occupational Hygiene and is a university lecturer at the Department of Occupational Health and Safety, School of Public Health, Iran University of Medical Sciences. Dr Bakand is currently undertaking a PhD research degree at The University of New South Wales, Sydney, Australia. This research explores the potential of in vitro methods using human cells as an alternative for toxicity testing of workplace air contaminants. The development of in vitro methods using human cells with appropriate air sampling and exposure techniques may lead to a better understanding of the interactions between human chemical exposure and toxic effects. The anticipated outcomes may also reduce the uncertainty factors in future risk assessment and standard setting for occupational and environmental air contaminants. 
contamination of test concentrations which can lead to interpretational errors. ${ }^{9}$ Different approaches have been pursued to overcome this problem. The evaporation of the more volatile test chemicals has been limited by overlaying the cells with a layer of mineral oil. ${ }^{8}$ An enclosed chamber was designed into which vapour of a specific concentration can be forced in order to inhibit the evaporation of test chemical from the culture medium. $^{10}$

Apart from the above-mentioned technical problems, it is essential to develop in vitro models that closely mimic the exposure patterns in vivo such as those occurring during inhalational exposures. ${ }^{11}$ Vapour inhalation is considered the most important means by which humans are exposed to volatile compounds, especially in the workplace environment. ${ }^{1,2}$ Therefore, the development of in vitro techniques that are comparable to in vivo environments during inhalation exposures needs to be encouraged. ${ }^{12}$ Some studies have attempted to simulate the exposure conditions similar to in vivo situations but, with considerable limitations, as in such test systems, cells are always covered by a less ${ }^{13}$ or more ${ }^{14}$ intervening layer of culture medium during the exposure time.

Recently, technology has become available that allows cells to be cultured on permeable porous membranes in transwell or snapwell inserts (suppliers: Costar, Falcon and Nunc). Once cells are established on the membrane, the upper layer of culture media can be removed, and the cells directly exposed to air contaminants. In a direct exposure technique at the air/ liquid interface target cells can be exposed to airborne contaminants continuously during the exposure time on their apical side, while being nourished from their basolateral side. Direct exposure of cells to airborne contaminants was initially achieved by growing cells on collagen-coated membranes located on special constructions, ${ }^{15}$ and more recently porous membranes in transwell inserts. ${ }^{16-18}$

In this study we developed a practical and reproducible in vitro technique for toxicity testing of volatile organic compounds. Xylene and toluene were selected as two important volatile organic compounds (VOCs) with widespread industrial applications. Inhalational and dermal exposures to vapours of these chemicals commonly occur in several workplace settings such as in printing, painting, rubber, leather and petrochemical industries. In addition, published in vivo toxicity data available for these chemicals, makes them ideal test candidates for in vitro method development and comparative purposes.

A static direct exposure technique for in vitro toxicity testing of selected volatile compounds was developed using cultured human cells on porous membranes in snapwell inserts. This new exposure technique not only avoids conventional technical problems in toxicity testing of volatile chemicals but may simulate more closely exposure patterns in vivo particularly during inhalation of vapours of volatile compounds. Considering the physico-chemical properties of selected volatile organic compounds (Table 1), standard test atmospheres of these chemicals were generated using a static method. In comparison to a dynamic method, static generation of test atmospheres of volatile compounds requires relatively simple equipment and procedures, making this method ideal for screening purposes. ${ }^{19}$ In a static direct exposure technique
Table 1 Physico-chemical properties of test chemicals

\begin{tabular}{|c|c|c|}
\hline $\begin{array}{l}\text { Physico-chemical } \\
\text { properties }\end{array}$ & $\begin{array}{l}\text { Xylene (CAS } \\
\text { No. 1330-20-7) }\end{array}$ & $\begin{array}{l}\text { Toluene (CAS } \\
\text { No. 108-88-3) }\end{array}$ \\
\hline Synonyms & Dimethyl benzene & Methylbenzene \\
\hline Appearance & Colourless liquid & Colourless liquid \\
\hline Chemical formula & $\mathrm{C}_{6} \mathrm{H}_{4}\left(\mathrm{CH}_{3}\right)_{2}$ & $\mathrm{C}_{6} \mathrm{H}_{5} \mathrm{CH}_{3}$ \\
\hline Molecular weight & 106.17 & 92.14 \\
\hline ity at $20^{\circ} \mathrm{C}$ & $0.86 \mathrm{~g} \mathrm{~mL}^{-1}$ & $0.866 \mathrm{~g} \mathrm{~mL}^{-1}$ \\
\hline Vapour pressure at $25^{\circ} \mathrm{C}$ & $8 \mathrm{~mm} \mathrm{Hg}$ & $28.4 \mathrm{~mm} \mathrm{Hg}$ \\
\hline Water solubility & Insoluble & Very slightly soluble \\
\hline
\end{tabular}

the physical stress on cells due to the dynamic flow of air was also omitted.

Toxic effects of generated airborne concentrations of test chemicals were studied in human target cells; A549-lung derived cell lines, HepG2-liver derived cell lines and skin fibroblasts using the MTS (Tetrazolium salt; Promega) and NRU (Neutral red uptake; Sigma) in vitro cell viability assays. Apart from establishment of airborne $\mathrm{IC}_{50}$ values for candidate volatile chemicals, development of this exposure technique may play a significant role in toxicity testing of volatile chemicals and inhalational toxicity studies in vitro.

\section{Materials and methods}

\subsection{Chemical compounds}

Toluene $\left(\mathrm{C}_{6} \mathrm{H}_{5} \mathrm{CH}_{3}\right)$, CAS\# 108-88-3, was purchased from APS Finechem, Australia, Analytical reagent. Xylene $\left(\mathrm{C}_{6} \mathrm{H}_{4}\left(\mathrm{CH}_{3}\right)_{2}\right)$, CAS\# 1330-20-7, was purchased from ChemSupply, Australia, Laboratory reagent. In vitro assay reagents were purchased from Promega (USA) and Sigma (USA).

\subsection{Cell types and culture conditions}

Three different human cells including: epithelial lung carcinoma cell lines (A549, ATCC No. CCL-185); hepatocarcinoma cell lines (HepG2, ATCC No. HB-8065) and skin fibroblasts isolated from skin biopsies of healthy individuals (Cytogenetics Department, Westmead Hospital, Sydney, Australia) were selected to represent different human organs of toxicological significance.

All cells were cultured in sterile, vented $75 \mathrm{~cm}^{2}$ cell culture flasks with DMEM/F12 (Dulbecco's modified eagle medium: Ham's F-12 nutrient mixture; Gibco, USA) culture media supplemented with $5 \%(\mathrm{v} / \mathrm{v})$ fetal calf serum (FCS; JS Bioscience, Australia) and 1\% (v/v) antibiotic (200 mM L-glutamine, $10000 \mathrm{U}$ Penicillin and $10 \mathrm{mg}$ Streptomycin per $\mathrm{ml}$; Sigma, USA). Cultured cells were kept at $37{ }^{\circ} \mathrm{C}$ in a humidified $5 \% \mathrm{CO}_{2}$ incubator.

For cytotoxicity experiments, newly confluent cell layers were enzymatically removed, using Trypsin/EDTA (Gibco, USA), and resuspended in culture medium. Cell viability was assessed by vital staining with trypan blue $(0.4 \%$ (w/v); Sigma, USA), and cell number was determined using a light microscope (Leitz Wetzlar, Germany). For culturing cells on membranes, appropriate cell numbers were determined in preliminary studies for each cell type and in vitro assays, based on the linearity range of cell concentration versus absorbance data. 
Human cells were grown on porous membranes $(0.4 \mu \mathrm{m})$ in snapwell inserts. The snapwell insert is a modified transwell culture insert with a $12 \mathrm{~mm}$ diameter providing a growth area of $1.12 \mathrm{~cm}^{2}$ (clear polyster Snapwell ${ }^{\mathrm{TM}}$ insert, 3801, Corning), supported by a detachable ring that was placed in a six well culture plate. Culture media and 1\% (v/v) HEPES buffer was added to both sides (bottom, $2 \mathrm{ml}$; top, $0.5 \mathrm{ml}$ ) of the membranes. The snapwell inserts in six well plates were incubated at $37{ }^{\circ} \mathrm{C}$ for one hour as an initial equilibrium time to improve cell attachment. Culture media was then removed from the top and replaced with fresh culture media $(0.5 \mathrm{ml})$ containing a cell suspension, $(20-30) \times 10^{4}$ cells, supplemented with $5 \%$ FCS, $1 \%$ antibiotics and $1 \%$ HEPES buffer. Cell cultures in six well plates were incubated at $37{ }^{\circ} \mathrm{C}$ in a humidified incubator for $24 \mathrm{~h}$. Cell attachment was observed under the light microscope (Leitz Wtzlar, Germany), medium was removed from both sides of the snapwell inserts and membranes washed with Hank's balanced salt solution (HBSS; Gibco, USA) from both sides (top, $0.5 \mathrm{ml}$; bottom, $2.0 \mathrm{ml}$ ). Cells on the membranes were exposed to airborne concentrations of test chemicals on their apical side while being nourished from their basolateral side, using the static exposure technique.

\subsection{Static exposure protocol}

A static technique for preparation of standard test atmospheres using a glass bottle has previously been reported. ${ }^{19}$ A specific quantity of a volatile liquid was introduced into the bottle onto a filter paper to assist evaporation. Glass was the preferred material as adsorption losses were very low and there was no diffusion of material through the vessel. ${ }^{19}$ In this study, standard test atmospheres of xylene and toluene were generated in glass chambers $(322 \pm 1.22 \mathrm{ml})$ using a static method.

After washing with HBSS, human cells grown on snapwell inserts were detached from their holders and placed into sterile individual glass wells. Each glass well contained $1.2 \mathrm{ml}$ of serum free culture media supplemented with 1\% HEPES buffer (Fig. 1). Two of these individual glass wells were placed in a single sterile chamber for subsequent analysis by two in vitro assays. Aliquots of test chemicals (ranging from 0, 2.5, $5.0,10.0,15.0,20.0$, or $30.0 \mu \mathrm{l})$ were introduced to the glass

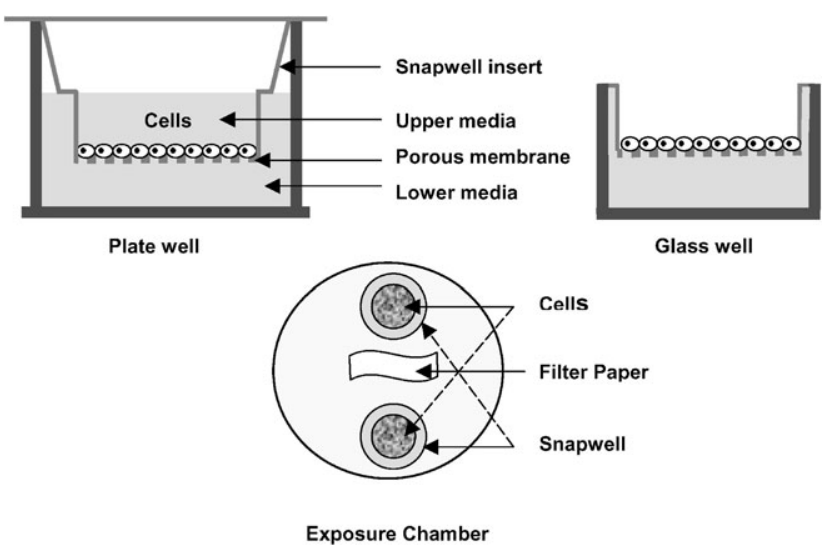

Fig. 1 Static exposure of human cells to airborne concentrations of VOCs. chambers onto the filter paper. Glass chambers were immediately closed, sealed with parafilm and placed on an orbital mixer incubator (50 RPM; Ratek Instruments, Australia) at $37{ }^{\circ} \mathrm{C}$. Each aliquot of volatile liquid was introduced into a single chamber. Human cells were exposed to various airborne concentrations of volatile test chemicals directly at the air/ liquid interface for $1 \mathrm{~h}$. At the end of the exposure time, snapwell inserts were removed and replaced in their holders within six well plates, Culture media supplemented with $1 \%$ HEPES buffer was added to both sides (top, $0.5 \mathrm{ml}$; bottom, 2 $\mathrm{ml}$ ) of the membranes. Cells were incubated for $24 \mathrm{~h}$ at $37{ }^{\circ} \mathrm{C}$ in a humidified incubator. At the end of the incubation time, cell viability was investigated using the MTS (tetrazolium salt) and NRU (neutral red uptake) assays.

\subsection{Cytotoxicity endpoints}

To assess the intrinsic cytotoxic effects of chemical substances, several in vitro tests have been developed by measuring different biological endpoints such as cell viability, cell metabolism and membrane leakage. ${ }^{11}$ In this study, two in vitro cytotoxicity assays measuring different endpoints were used.

The Promega CellTiter $96^{\mathbb{B}} \mathrm{AQ}_{\text {ueous }}$ Non-Radioactive Cell Proliferation Assay was used to measure the toxicity of test chemicals by determining the number of viable cells in culture. $^{20}$ This MTS (3-(4,5-dimethylthiazol-2-yl)-5-(3-carboxymethoxyphenyl)-2-(4-sulfophenyl)- $2 H$-tetrazolium) assay is based on the ability of viable cells to convert a soluble tetrazolium salt to a formazan product. This assay has been used in our laboratory for toxicity testing of chemicals and airborne contaminants. ${ }^{21,22}$ The detection reagent is composed of solutions of MTS (Tetrazolium salt; Promega, USA) and PMS (an electron coupling reagent; Phenazine methosulfate; Sigma, USA). Both substances were initially dissolved in DPBS (Dulbecco's Phosphate Buffered Saline; Gibco, USA) at ratios of $2: 1$ (w/v; MTS: DPBS) and $0.92: 1$ (w/v; PMS: DPBS $)$, filter sterilized $(0.22 \mu \mathrm{m})$ and stored separately in light protected containers at $-20{ }^{\circ} \mathrm{C}$.

After $24 \mathrm{~h}$ post incubation of cells, culture media was removed and replaced with fresh culture media from the bottom $(2 \mathrm{ml})$ and top $(0.4 \mathrm{ml})$ of the membranes. The MTS and PMS reagents were thawed and mixed in a ratio of $20: 1$ (MTS : PMS) immediately before being added to the cells. The MTS/PMS reagent $(100 \mu \mathrm{l})$, was added to the cells on the top of the membrane and incubated at $37^{\circ} \mathrm{C}$ for $1 \mathrm{~h}$. After the incubation period, aliquots of $40 \mu \mathrm{l}$ from the top of the membranes were transferred to the 384 well plates in 6-8 replicates and absorbance was recorded at $492 \mathrm{~nm}$ using a multiplate reader (Multiskan Ascent, Thermo Labsystems, Finland) against controls.

The neutral red (3-amino-7-dimethyl-amino-2-methylphenazine hydrochloride) uptake (NRU; Sigma) assay is a cell survival/viability technique based on the ability of viable cells to incorporate and bind supravital neutral red dye. This assay used to measure the cytotoxicity of test chemicals. After $24 \mathrm{~h}$ post incubation of cells, culture media was removed and membranes washed with HBSS. Culture media was added on the bottom of the membranes $(2 \mathrm{ml})$. Neutral red medium (80 $\mathrm{g} \mathrm{ml}^{-1}$ media) prepared from the previous day and kept 
at $37{ }^{\circ} \mathrm{C}$, was centrifuged for $5 \mathrm{~min}$ at $1500 \times g$ and the supernatant filter sterilized $(0.22 \mu \mathrm{l})$. The NRU solution $(0.5$ $\mathrm{ml}$ ) was added into the top part of the membranes, and cells were incubated for $3 \mathrm{~h}$ at $37^{\circ} \mathrm{C}$. After the incubation period, the medium was removed and cells fixed with fixative solution from the top $(0.5 \mathrm{ml})$ of the membranes for no longer than $30 \mathrm{~s}$. Membranes were rinsed with HBSS from the top $(0.5 \mathrm{ml})$ and bottom $(2 \mathrm{ml})$, and assay solubilization solution $(0.5 \mathrm{ml})$ was added to the membranes (top). The plate was shaken for 10 min using an orbital mixer (Ratek Instruments, Australia) and aliquots of $100 \mu \mathrm{l}$ were transferred into 96 well plates in 3-4 replicates. The absorbance was recorded at $540 \mathrm{~nm}$ with a microtiter plate reader (Multiskan MS, Labsystems, Finland) against controls.

\subsection{Controls}

For each in vitro experiment, two controls were set up under identical conditions including: $\mathrm{IC}_{0}(0 \%$ inhibitory concentration; cells only) and; $\mathrm{IC}_{100}(100 \%$ inhibitory concentration; media only) exposed to air only during exposure time.

For both in vitro assays percentage of cell viability at each test concentration was calculated from eqn (1):

$$
\begin{aligned}
& \% \text { cell viability }= \\
& \left(\frac{\text { mean absorbance of exposed cells }}{\text { mean absorbance of unexposed control cells }}\right) \times 100
\end{aligned}
$$

\subsection{Calculation of airborne test concentrations}

In a static system, the concentration of the generated test atmospheres can be calculated. ${ }^{19}$ Moreover, the test atmosphere can be sampled for gas chromatographic analysis if required using a gas-tight syringe. In this study, the airborne concentrations of volatile organic solvents, produced by evaporation of a known amount of volatile liquid, was calculated as per eqn (2). ${ }^{19}$

$$
\mathrm{ppm}=\left(\frac{10^{6} w / \mathrm{MW}}{V / V_{\mathrm{m}}}\right)
$$

where $w=$ weight of volatile test liquid introduced, in $\mathrm{g}$; $\mathrm{MW}=$ molecular weight of test liquid, in $\mathrm{g} ; V_{\mathrm{m}}=$ gram molecular volume, in 1 , of the mixture under ambient conditions; and $V=$ total volume of mixture, in 1 .

The molar gas volume was calculated for the ambient temperature and pressure using eqn (3). ${ }^{19}$

$$
V_{\mathrm{m}}=24.45\left(\frac{760}{P}\right)\left(\frac{t+273.15}{298.15}\right)
$$

where $24.45=$ gram molecular volume, in 1 , under standard conditions of $760 \mathrm{~mm} \mathrm{Hg}, 25{ }^{\circ} \mathrm{C} ; P=$ ambient pressure, in $\mathrm{mm} \mathrm{Hg}$; and $t=$ ambient temperature, in ${ }^{\circ} \mathrm{C}$.

\subsection{Statistical analysis}

Statistical analyses were performed using Microsoft Excel 2002 and SPSS (version 12.0) Software. Analysis of variance (ANOVA) was used to compare the mean $\mathrm{IC}_{50}$ values of test a) Skin fibroblasts

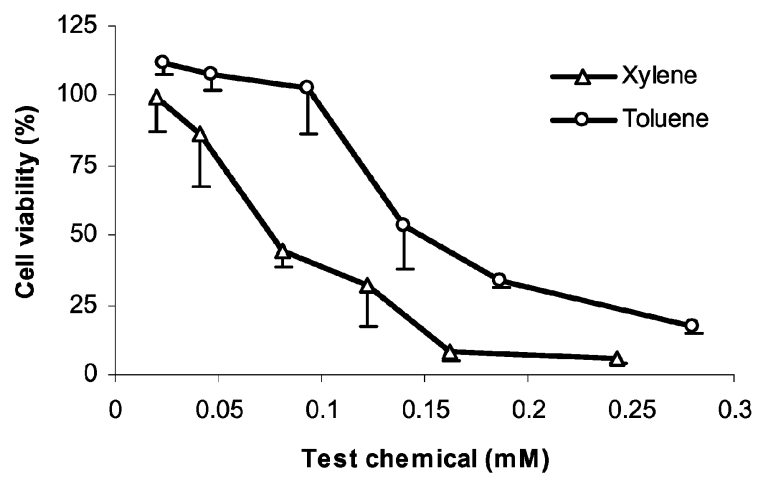

b) A549

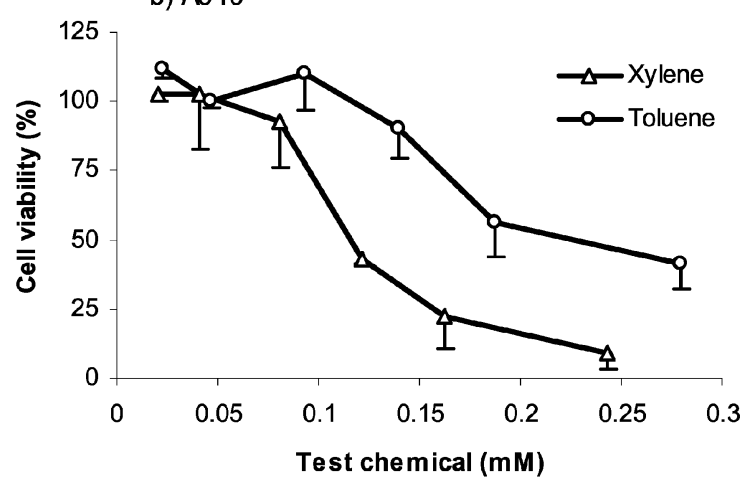

c) HepG2

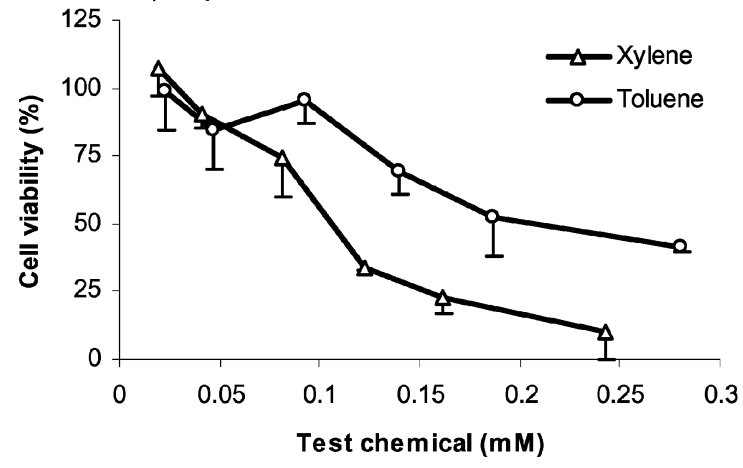

Fig. 2 The concentration-effect curves of test chemicals on human cells using the MTS assay. (a) Skin fibroblasts; (b) A549; (c) HepG2.

chemicals in three cell types, followed by multiple comparisons (Post Hoc Tests, Tukey HSD) to identify which cell type was statistically significantly different. Differences were considered as statistically significant at $p<0.05$.

\section{Results and discussion}

The concentration-effect curves of test chemicals on different human cells are presented for the MTS (Fig. 2) and NRU (Fig. 3 ) in vitro cytotoxicity assays. Each experimental curve represents the average of a series of three different experiments $(n=24)$. Airborne concentration related effects of xylene and toluene were observed in all human cells tested.

The airborne $\mathrm{IC}_{50}$ values of test chemicals in three different human cells with two in vitro assays are reported in Table 2. 


\section{a) Skin fibroblast}

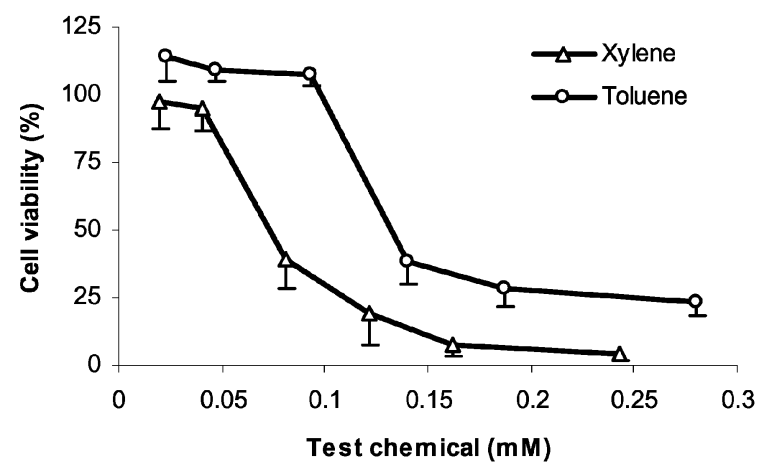

b) A549

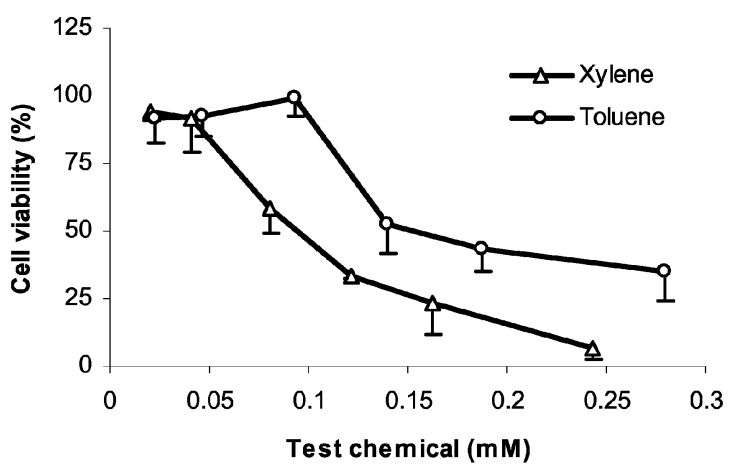

c) HepG2

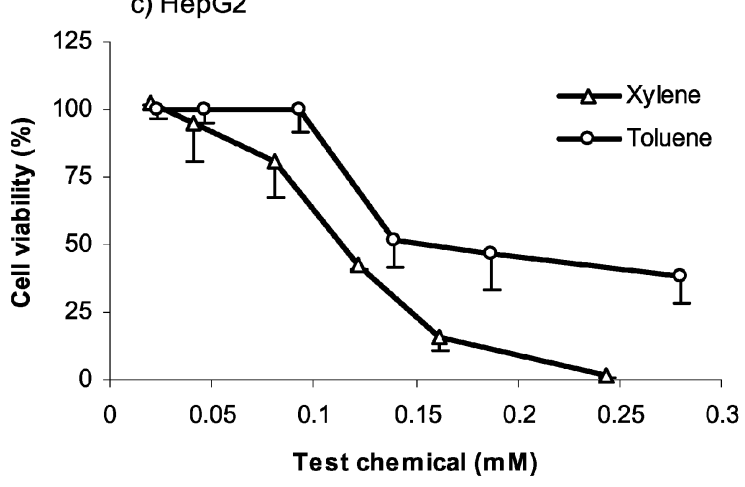

Fig. 3 The concentration-effect curves of test chemicals on human cells using the NRU assay. (a) Skin fibroblasts; (b) A549; (c) HepG2.

The mean $(m)$ and standard deviations (SD) were calculated as a percentage of controls. For airborne $\mathrm{IC}_{50}$ extrapolations both experimental and exponential curves were considered and airborne concentrations were calculated as described in Section 2.6.
Cell viability was significantly reduced in a dose-dependent manner after exposure of human cells to airborne concentrations of selected volatile organic solvents tested in both in vitro assays. Rather than single airborne concentration studies, airborne concentration-effect curves of test chemicals were achieved using a static direct exposure method and airborne $\mathrm{IC}_{50}$ values were derived for selected test chemicals (Table 2). Xylene appeared to be more toxic than toluene in all cell types tested with both MTS and NRU assays.

The lowest airborne $\mathrm{IC}_{50}$ values were measured for skin fibroblasts for both test chemicals with both assays. Nevertheless, after testing with one way ANOVA, no statistically significant difference was observed between sensitivity of cell types except for toxicity of xylene with the MTS assay $(p<$ $0.01)$. In this case, multiple comparisons revealed that the sensitivity of skin fibroblasts was significantly different from A549 cell lines $(p<0.05)$. While both in vitro cell viability assays indicated good sensitivity, the NRU assay appeared to be more sensitive than the MTS assay for toxicity testing of volatile test chemicals, in all human cells tested which may relate to alteration of lysosomal membrane by test chemicals, particularly toluene.

No published in vitro airborne toxicity data could be sourced for xylene and toluene. However, inhalational in vivo toxicity data for both test chemicals have been reported in rat by the NIOSH Registry of Toxic Effects of Chemical Substances (RTECS). The $\mathrm{LC}_{50}$ (50\% Lethal Concentration) values of xylene $(5000 \mathrm{ppm})$ and toluene $(13,000 \mathrm{ppm})$ have been reported in rats following $4 \mathrm{~h}$ exposure. ${ }^{23,24}$ Based on our in vitro results, $\mathrm{IC}_{50}$ values for xylene $(5350-8200 \mathrm{ppm})$ and toluene (10500-16600 ppm) were determined after $1 \mathrm{~h} \mathrm{ex-}$ posure (Table 2). An in vitro/in vivo comparison indicates that the in vitro toxicity findings in the present study are in good correlation with inhalational in vivo published data for both volatile organic solvents. Considering the exposure time differences, our results obtained using in vitro test methods may also appear to be more sensitive. This high correlation of results confirms that the static direct exposure technique has the potential to be used for in vitro toxicity assessment of volatile organic compounds.

The development of this in vitro exposure technique offers a practical and reproducible method for toxicity testing of selected VOCs. Our findings suggest that the static direct exposure technique may be used for toxicity screening, ranking and quantitative toxicity testing of volatile organic compounds. This method can potentially be applied for inhalational and dermal toxicity testing of volatile compounds where exposure patterns in vivo are more closely simulated by this technique.

Table 2 Airborne $\mathrm{IC}_{50}$ values of test chemicals in three human cells

\begin{tabular}{|c|c|c|c|c|}
\hline \multirow[b]{3}{*}{ Human cell types } & \multicolumn{4}{|c|}{$\mathrm{IC}_{50}$ of test chemicals (ppm; $m \pm \mathrm{SD}$ ) } \\
\hline & \multicolumn{2}{|l|}{ Xylene } & \multicolumn{2}{|l|}{ Toluene } \\
\hline & MTS & NRU & MTS & NRU \\
\hline Fibroblasts & $5750 \pm 433.0$ & $5350 \pm 327.9$ & $11200 \pm 1044.0$ & $10500 \pm 526.8$ \\
\hline A549 & $8200 \pm 953.9$ & $7400 \pm 1389.2$ & $16600 \pm 3423.1$ & $12100 \pm 2256.7$ \\
\hline HepG2 & $7200 \pm 888.8$ & $7000 \pm 1113.6$ & $16000 \pm 3747.7$ & $12300 \pm 2262.7$ \\
\hline
\end{tabular}




\section{Abbreviations}

A549, human epithelial lung carcinoma cell lines; ANOVA, analysis of variance; ATCC, American Type Culture Collection; CAS, Chemical Abstracts Service; DMEM/F12, Dulbecco's modified eagle medium: Ham's F-12 nutrient mixture; DPBS, Dulbecco's phosphate buffered saline; EDTA, ethylene diamine tetra acetic acid; FCS, fetal calf serum; HBSS, Hank's balanced salt solution; HEPES, $N$-(2-hydroxyethyl)-piperazine- $N^{\prime}$-2-ethanesulfonic acid; HepG2, hepatocarcinoma cell lines $\mathrm{IC}_{50}, 50 \%$ inhibitory concentration; $\mathrm{LC}_{50}, 50 \%$ lethal concentration; MTS, (3-(4,5-dimethylthiazol-2-yl)-5-(3-carboxymethoxyphenyl)-2-(4-sulfophenyl)-2 $H$-tetrazolium salt); NIOSH, National Institute for Occupational Safety and Health; NRU, neutral red uptake; PMS, phenazine methosulfate; RTECS, The Registry of Toxic Effects of Chemical Substances; VOC, volatile organic compounds.

\section{Acknowledgements}

This research was supported by a postgraduate scholarship (S. Bakand) from the Iranian Ministry of Health and Medical Education. The authors would also like to thank Dr Zhanhe Wu (Westmead Hospital, Sydney) for supplying the human cells and Dr Paul Thomas (Department of Medicine, Prince of Wales Clinical School) and Dr Maria Kavallaris (Experimental Therapeutics Program Children's Cancer Institute Australia for Medical Research) for providing of the A549 cell lines.

\section{References}

1 N. H. Stacey and C. Winder, in Occupational Toxicology, ed. C. Winder and N. H. Stacey, CRC Press, Boca Raton, 2nd edn., 2004, ch. 14 , pp. 372-398.

2 R. C. Spiker and G. B. Morris, in Principles and Methods of Toxicology, ed. A. W. Hayes, Taylor and Francis, New York, 2001, ch. 12 , pp. 531-564.

3 D. M. Stark, C. Shopsis, E. Borenfreund and H. Babich, Food Chem. Toxicol., 1986, 24 6-7, 449-455.
4 J. M. FrazierJ. A. Bradlaw, A report of the CAAT technical workshop of may 17-18, Technical Report No 1, 1989.

5 F. Zucco, I. De Angelis and A. Stammati, in Animal cell culture techniques, Springer Lab Manual, ed. M. Clynes, Springer-Verlag, Berlin, 1998, ch. 21, pp. 395-422.

6 P. J. Dierickx, Toxicol. in Vitro, 2003, 17(5-6), 797-801.

7 S. S. Al-Ghamdi, M. J. Raftery and M. M. Yaqoob, Toxicol. in Vitro, 2003, 17(3), 335-341.

8 A. Yang, D. L. Cardona and F. A. Barile, Toxicol. in Vitro, 2002, 16(1), 33-39.

9 G. Ciapetti, D. Granchi, E. Verri, L. Savarino, S. Stea, F. Savioli, A. Gori and A. Pizzoferrato, Biomed. Mater. Res., 1998, 39(2), 286-291.

10 K. T. Geiss, J. M. Frazier and D. E. Dodd, Proceedings of the 12th Halon Options Technical working Conference, NIST Special Publication 984, 2002.

11 S. Bakand, C. Winder, C. Khalil and A. Hayes, Inhalation Toxicol., 2005, 17, 775-787.

12 C. R. Lambre, M. Auftherheide, R. E. Bolton, B. Fubini, H. P. Haagsman, P. M. Hext, M. Jorissen, Y. Landry, J. P. Morin, B. Nemery, P. Nettesheim, J. Pauluhn, R. J. Richards, A. E. M. Vickers and R. Wu, Altern. Lab. Anim., 1996, 24, 671-681.

13 H. Muckter, M. Zwing, S. Bader, T. Marx, E. Doklea, B. Liebl, B. Fichtl and M. Georgieff, J. Pharmacol. Toxicol., 1998, 40, 63-69.

14 P. Bonsi, F. Zucco and A. Stammati, Altern. Lab. Anim., 2002, 30, 241-247.

15 L. C. Chen, C. P. Fang, Q. S. Qu, J. M. Fine and R. B. Schlesinger, Fundam. Appl. Toxicol., 1993, 20(2), 170-176.

16 J. W. Knebel, D. Ritter and m. Aufderheide, Toxicol. Lett., 1998, 96-97, 1-11.

17 S. Diabate, S. Mulhopt, H. R. Paur and H. F. Krug, Ann. Occup. Hyg., 2002, 46(supplement 1), 382-385.

18 M. Aufderheide, J. W. Knebel and D. Ritter, Toxicol. Lett., 2003, 140-141, 205-211.

19 B. E. Saltzman, in The occupational environment-its evaluation and control, ed. S. R. Dinardi, AIHA, Virginia, 1997, ch. 7, pp. 131-154.

20 Promega, CellTiter 96 ${ }^{\mathbb{}}$ Aqueous Non-Radioactive Cell Proliferation Assay: Technical Bulletin No 169, Promega Corporation, Madison, USA, 2001.

21 G. Malich, B. Markovic and C. Winder, Toxicology, 1997, 124, 179-192.

22 S. Bakand, A. Hayes, C. Winder, C. Khalil and B. Markovic, Toxicol. Ind. Health, 2005, 21, 147-154.

23 NIOSH, The Registry of Toxic Effects of Chemical Substances, Toluene, RTECS \# XS5250000, 2004.

24 NIOSH, 2004b, The Registry of Toxic Effects of Chemical Substances, Xylene, RTECS \# ZE2100000, 2004. 